\title{
DRUG ABSORPTION FROM THE GASTROINTESTINAL TRACT AND IMMUNITY: THE MECHANISM OF THE DECREASED ABSORPTION OF SALICYLIC ACID DURING SYSTEMIC ANAPHYLAXIS. I
}

\author{
Akira Yamamoto, ${ }^{*}$ Junzo Nakamura, ${ }^{* *}$ Shigeyuki Takada, Minako Takeda, Mitsuru \\ HASHIDA, ${ }^{*}$ TOSHIKIRO KIMURA, ${ }^{* * *}$ AND HITOSHI SEZAKI* \\ Faculty of Pharmaceutical Sciences, Kyoto University, * Yoshida Shimoadachi-cho, Sakyo-ku, Kyoto, \\ 606, Japan, Faculty of Pharmaceutical Sciences, Nagasaki University, ${ }^{* *} 1-14$, Bunkyo-cho, Nagasaki, \\ 852, Japan and Faculty of Pharmaceutical Sciences, Okayama University, ${ }^{* * *}$ 1-1-1, Tsushima-naka, \\ Okayama, 700, Japan
}

(Received February 16,1984)

Previous studies have demonstrated the decrease of intestinal salicylic acid absorption in ovalbumin-immunized rats during systemic anaphylaxis.

In the present study, the mechanism whereby systemic anaphylaxis interferes with the intestinal absorption of salicylic acid was studied. The $\mathrm{pH}$ of the luminal solution was not affected by the intravenous challenge with ovalbumin. A significant increase of the intraluminal protein was observed in rats under systemic anaphylaxis. However, there was no significant difference between ovalbumin-treated rats and saline-treated ones on the binding of salicylic acid with intraluminal macromolecular substances. Enhanced mucus release in the perfusate was also observed in sensitized rats but the extent of decrease in absorption of salicylic acid did not correlate with the increase in amount of the intraluminal mucus in the same animals. In addition, no significant effect was observed on the uptake by the intestinal everted sac of rats with systemic anaphylaxis. These findings suggested that mucus as well as protein is not responsible for the decrease of absorption of salicylic acid induced by systemic anaphylaxis.

From these observations, it would appear that the circulatory changes in the gastrointestinal tract may play an important role in the decreased absorption of salicylic acid during systemic anaphylaxis.

Keywords - intestinal absorption; immunization; anaphylaxis; ovalbumin; salicylic acid; mucosal permeability; mucus; protein binding; Evans Blue

\section{INTRODUCTION}

The past several years have witnessed increasing interest in the field of immunology. It is apparent that the unique local immune system of the intestinal epithelial surfaces act as a first defense against invasion by organisms and other substances which may be involved in the pathogenesis of local intestinal or systemic disease states. $^{1,2)}$

This laboratory has been pursuing studies involving the immunological factors that can influence the absorption of drugs from the gut. In earlier studies, it was reported that the disappear- ance of salicylic acid from the luminal solution was significantly decreased in ovalbuminimmunized rats and these results were related to the anti-ovalbumin antibody formation detected passive cutaneous anaphylactic reactions. ${ }^{3,4)}$ However, its physiological mechanisms remain unknown. Therefore, the present research was aimed at the elucidation of the mechanism of the decreased absorption of salicylate. In this case, it may be considered that all the mechanism can be classified on the basis of the drug absorption process into three parts. That is; (1) intraluminal interactions (2) mucosal permeability 
(3) circulatory changes. In particular, the present study dealt with the first and second steps of the drug absorption process, i.e., (1) intraluminal interactions (2) mucosal permeability, and the possible involvement of these mechanisms was investigated.

\section{MATERIALS AND METHOD}

Materials - Ovalbumin and bovine $\gamma$ globulin were purchased from Sigma Chemical Co. Salicylic acid and all other reagents used in these experiments were of reagent grade obtained from Nakarai Chemical Co.Japan.

Preparation of Drug Solution - The isotonic buffer solution of $\mathrm{pH} 6.5$ was prepared from $0.123 \mathrm{M} \mathrm{Na}_{2} \mathrm{HPO}_{4}$ and $0.163 \mathrm{M} \mathrm{NaH}_{2} \mathrm{PO}_{4}$. Salicylic acid was dissolved in this buffer solution at the concentration of $1 \mathrm{mM}$ for absorption studies.

Animals and Immunization — Male W istar albino rats ranging in weight from 150 to $200 \mathrm{~g}$ were used in these studies. The rats, which had been on a diet free of ovalbumin and bovine $\gamma$ globulin, were immunized according to the following schedule. One milligram of ovalbumin or bovine $\gamma$-globulin dissolved in $0.25 \mathrm{ml}$ of saline $(0.9 \% \mathrm{w} / \mathrm{v})$ was emulsified with an equal volume of incomplete Freund's adjuvant and was injected intraperitoneally to rats under light ether anesthesia. Animals were immunized once to three times and absorption studies were carried out one week after the final immunization.

Absorption Studies - Absorption studies were performed at $\mathrm{pH} 6.5$ using in situ perfusion technique and in vitro uptake by everted sac.

In Situ Perfusion Technique: The procedure of the in situ absorption study in the rat small intestine was the same as that reported in our previous papers. ${ }^{5)}$ Briefly, animals were anesthetized with pentobarbital, given intraperitoneally, and the small intestine was cannulated for recirculation. The entire length of the small intestine, from the pylorus to the ileo-cecal junction, was used for the absorption studies. The bile duct was ligated in all experiments. Ovalbumin dissolved in $0.25 \mathrm{ml}$ of saline was adminis- tered into a right femoral vein for $5 \mathrm{~min}$. After a constant period, $40 \mathrm{ml}$ of a drug solution kept at $37^{\circ} \mathrm{C}$ was recirculated through the intestine at a rate of $5 \mathrm{ml} / \mathrm{min}$ using peristaltic pump. At the end of an experimental period, the perfusate solution in the small intestine was withdrawn as completely as possible, and the intestinal lumen was washed with $\mathrm{pH} 6.5$ buffer solution. The washings were combined with the perfused solution and made up to $100 \mathrm{ml}$ with $\mathrm{pH} 6.5$ buffer solution. The amount of drug disappeared from the lumen was calculated as the difference between the amount of the drug in the initial and the final solutions.

In Vitro Uptake by Everted Sac: Ovalbuminimmunized rats were anesthetized with pentobarbital, given intraperitoneally, and the entire length of the small intestine, from the pylorus to ileo-cecal junction, was washed with $\mathrm{pH} 6.5$ buffer solution. Then, ovalbumin dissolved in $0.25 \mathrm{ml}$ of saline was administered into their femoral veins. After $10 \mathrm{~min}$, the small intestine was isolated and cut into two segments. The upper $25 \mathrm{~cm}$ segment (jejunum) and the lower $25 \mathrm{~cm}$ segment (ileum) were everted by means of a wire inserted through the lumen and ligated at both ends. Each segment was incubated in 10 $\mathrm{ml}$ of $\mathrm{pH} 6.5$ buffer solution at $37^{\circ} \mathrm{C}$ for $5 \mathrm{~min}$ under $95 \% \mathrm{O}_{2}+5 \% \mathrm{CO}_{2}$ gas flow. The amount disappeared from the incubation medium was calculated by the difference in concentration of the drug between the initial and the final solutions.

Exsorption Studies - The exsorption of Evans Blue to the gut lumen during systemic anaphylaxis was studied by the modified method described in previous reports from this laboratory. ${ }^{6-9)}$ The operation was the same as the absorption studies. After the intravenous administration of Evans Blue ( $5 \mu \mathrm{mol} / 0.5 \mathrm{ml}$ in saline), ovalbumin was also administered intravenously to the immunized rats. Then, the small intestine was recirculated with $\mathrm{pH} 6.5$ buffer solution for $15 \mathrm{~min}$ at the rate of $5 \mathrm{ml} / \mathrm{min}$. At the end of recirculation, the amount of the dye in the perfusate was determined spectrophotometrically. 
Protein and Mucus Determination in the Perfusate - The operation and the perfusion technique were the same as in situ absorption studies. After recirculation of $\mathrm{pH} 6.5$ buffer solution for $15 \mathrm{~min}$ in immunized and normal rats, an aliquot of the perfusate was centrifuged for $10 \mathrm{~min}$ at $3000 \mathrm{rpm}$. After centrifugation, the supernatant was assayed as described below.

Binding of Salicylic Acid with Macromolecular Substances in Perfusate — Two method were adopted to estimate the binding of this drug with macromolecular substances in perfusate.

Equilibrium Dialysis Method: Salicylic acid was dissolved in $\mathrm{pH} 6.5$ buffer solution at the concentration of $10^{-3} \mathrm{M}$. Four $\mathrm{ml}$ of the drug solution was placed in a $10 \mathrm{ml}$ centrifuge tube as the outer fluid. cellulose tube (Visking Co. \# 8/32) containing $2 \mathrm{ml}$ of the perfusate was immersed in a centrifuge tube and equilibrated for $72 \mathrm{~h}$ at $4^{\circ} \mathrm{C}$. After equilibration, the concentration of salicylic acid in the outer layer was determined spectrophotometrically as described below.

Ultrafiltration Method: Ultrafiltration was performed by means of Ultrafree (Millipore Co.). A completely evaculated $1 \mathrm{ml}$ tuberculin syringe, without needle, was fastened to the bottom of the filter unit. An aliquot of the sample was pippeted into the reservoir cup and ultrafiltered in an unstirred mode into a $1 \mathrm{ml}$ tuberculin syringe. The driving force of the ultrafiltration was obtained by aspiration of the syringe plunger to provide a vacuum source. Then, $0.5 \mathrm{ml}$ ultrafiltrate obtained was assayed to determine the free drug concentration.

Analytical Methods — Salicylic Acid: Three $\mathrm{ml}$ of sample solution was acidified with $0.1 \mathrm{ml}$ of $35 \% \mathrm{HCl}$ and extracted with $7 \mathrm{ml}$ of chloroform. An aliquot of the organic phase was then shaken with $0.1 \mathrm{~N} \mathrm{NaOH}$ and the optical density of the aqueous phase was determined spectrophotometrically at $295 \mathrm{~nm}$.

Protein: Protein was estimated by the method of Lowry et al. ${ }^{10)}$ using bovine serum albumin as a standard.

Mucus: Mucus was determined by anthrone method using D-glucose as a standard and a colorimetric reading at $620 \mathrm{~nm} .{ }^{11)}$

Evans Blue: After recirculation, the perfusate was centrifuged for $10 \mathrm{~min}$ at $2500 \mathrm{rpm}$, and then the supernatant was determined spectrophotometrically at $606 \mathrm{~nm}$.

Statistical Analyses - Results were expressed as the mean \pm standard deviation (S.D.). Statistical analyses were performed using student's $t$ test.

\section{RESULTS}

The absorption of salicylic acid in rats having different amount of intravenous challenge with ovalbumin is shown in Fig. 1. Animals were challenged with $0.1,0.2,0.5$, and $1 \mathrm{mg}$ of the antigen, respectively. A significant decrease of drug absorption was observed in all cases (all the results were $p<0.001$ ), although less effect was obtained in rats challenged with $0.1 \mathrm{mg}$ of ovalbu$\min$.

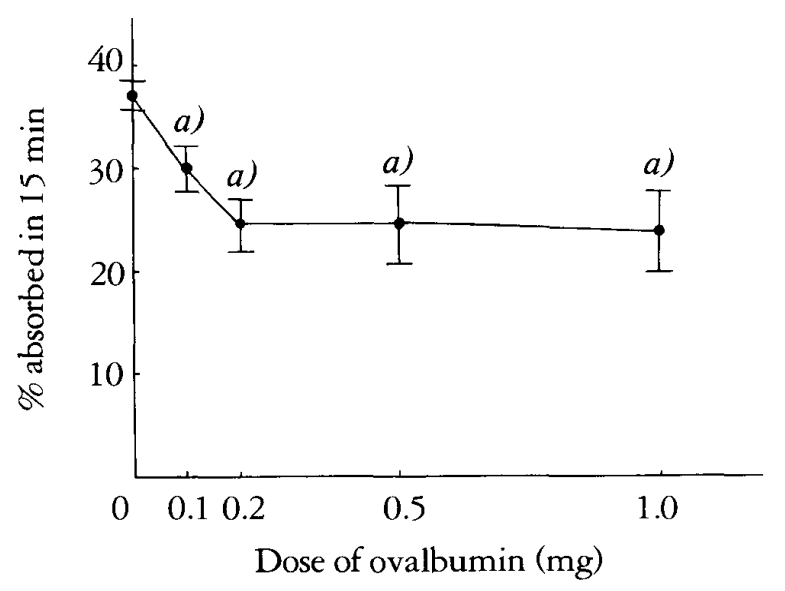

FIG. 1. Effect of the Challenging Antigen Dose on the Intestinal Absorption of Salicylic Acid in Ovalbumin-Immunized Rats

Animals were challenged with various dose of the antigen intravenously before the start of intestinal recirculation. Absorption studies were carried out by means of in situ perfusion technique. Results are expressed as the mean $\pm S$. $D$. of at least 4 animals. Statistical significance are observed in all cases in comparison to controls. a) $p<0.001$. 
In order to study whether this phenomenon is reversible or not, in situ absorption studies were carried out immediately, 15, $30 \mathrm{~min}, 1$, and 3-4 $h$ after the intravenous challenge with ovalbumin in immunized rats. As shown in Fig. 2, a maximum response was obtained $15 \mathrm{~min}$ after the challenge, but it gradually restored, and

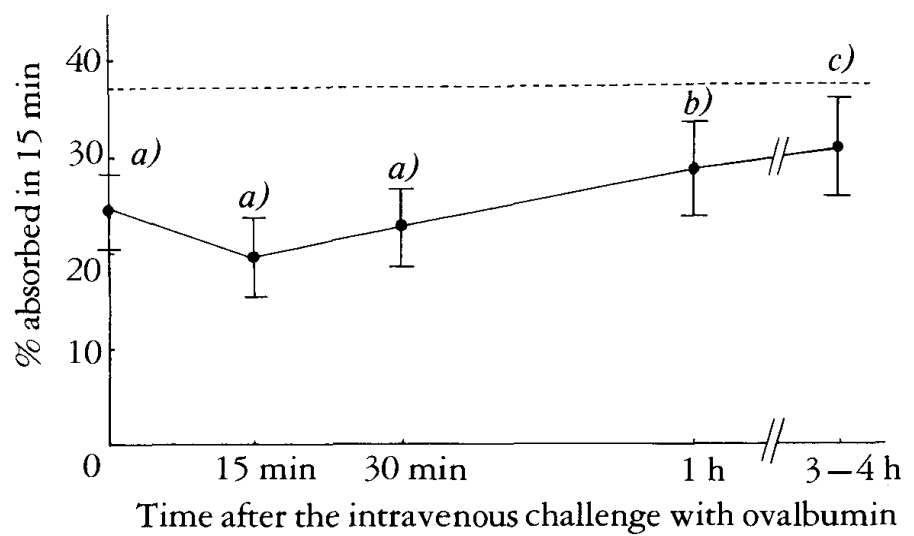

FIG. 2. Effect of Duration of the Anaphylactic Reaction on the Intestinal Absorption of Salicylic Acid in Ovalbumin-Immunized Rats

Animals were challenged with $0.5 \mathrm{mg}$ of ovalbumin intravenously and absorption studies were carried out immediately, 15, $30 \mathrm{~min}, 1$, and 3-4 $h$ after the antigen challenge. Results are expressed as the mean $\pm S$. D. of at least 4 animals. a) $p<0.001, b) p<0.02$, c) not significantly different, compared with the control. Dotted line represents the mean absorption \% of the controls (saline treatment). finally reached to the control levels until 3-4h.

Among the mechanisms of the decreased salicylic acid absorption, interactions of salicylic acid with intraluminal biological substances were investigated by means of in situ perfusion technique. Table I summarized the amount of intraluminal protein released during recirculation of $\mathrm{pH} 6.5$ buffer solution in rats under systemic anaphylaxis. Ovalbumin was injected intravenously at $0.1,0.2,0.5$, and $1 \mathrm{mg}$, respectively, to clarify the effect of dose on the protein release. No significant increase in the protein release was observed by the intravenous challenge with 0.1 and $0.2 \mathrm{mg}$ of ovalbumin. However, there was a marked increase in the amount of the protein when 0.5 and $1 \mathrm{mg}$ of ovalbumin was administered intravenously. In order to prove that the enhanced intraluminal protein release is induced by systemic anaphylaxis, appearance of the protein in the perfusate was also determined in normal rats. The results are also given in Table I. In normal rats, no significant difference was observed in the amount of intraluminal protein after the intravenous antigen challenge. In the experiment of the protein determination in the perfusate, the changes in the $\mathrm{pH}$ value was examined simultaneously. No significant change of the $\mathrm{pH}$ value was obtained by the intravenous challenge with ovalbumin compared to the control (In both case, $\mathrm{pH}$ value was about 6.5).

The increased protein in the perfusate might be due to the leakage of the plasma protein into

TABLE I. The Amount of Intraluminal Protein during Systemic Anaphylaxis

\begin{tabular}{ccc}
\hline \hline Immunization & Challenge & Amount of protein $(\mu \mathrm{g} / \mathrm{ml})$ \\
\hline OA & Saline & $193 \pm 54(6)$ \\
OA & OA $0.1 \mathrm{mg}$ & $\left.239 \pm 65(6)^{a}\right)$ \\
OA & OA $0.2 \mathrm{mg}$ & $\left.244 \pm 72(8)^{a}\right)$ \\
OA & OA $0.5 \mathrm{mg}$ & $405 \pm 86(6) b)$ \\
OA & OA $1 \mathrm{mg}$ & $405 \pm 40(6)^{b}$ \\
- & Saline & $204 \pm 48(6)$ \\
- & OA 0.5 mg & $185 \pm 56(6)^{a)}$ \\
\hline
\end{tabular}

Results are expressed as the mean $\pm S . D$. with the number of experiments in parentheses.

a) not significantly different, $b$ ) $<0.001$, compared with the control. $O A=$ ovalbumin. 
the gut lumen during systemic anaphylaxis. Therefore, Evans Blue was chosen as a marker compound to determine whether plasma protein might leak out from the vessels. As demonstrated in Fig. 3, a significant increase in leaks of the dye was observed by the intravenous challenge with 0.5 and $1 \mathrm{mg}$ of ovalbumin compared to the control value, but was not observed by the $0.1 \mathrm{mg}$ antigen administration. A slight leakage of Evans blue appeared by the intravenous challenge with the foreign antigen, bovine $\gamma$ globulin, but there was no statistical significance compared to saline treatment as the control.

Moreover, it can be considered that intralumi-

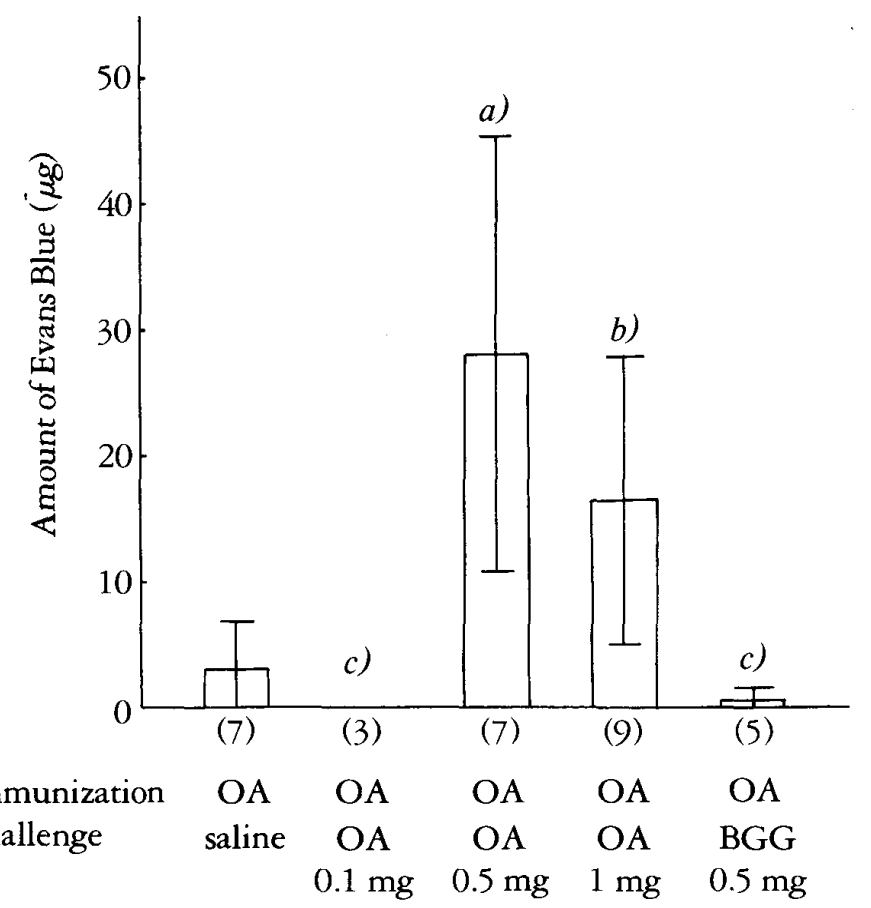

FIG. 3. Effect of the Challenging Antigen Dose on the Leakage of Evans Blue in OvalbuminImmunized Rats

Evans Blue (5 umol/ $0.5 \mathrm{ml}$ in saline) was administered intravenously before the antigen challenge and the small intestine was perfused with $\mathrm{pH}$ 6.5 buffer solution for $15 \mathrm{~min}$ at the rate of 5 $\mathrm{ml} / \mathrm{min}$. Results are expressed as the mean $\pm S$. D. of at least 3 animals. Numbers in parentheses represent the number of experiments. a) $p<0.01$, b) $p<0.02, c)$ not significantly different, compared with the control. $O A=$ ovalbumin, $B G G=-$ bovine $\gamma$-globulin. nal protein might influence the absorption of salicylic acid by increasing protein binding of the drug. Therefore, the binding of salicylic acid with macromolecular substances in the perfusate was estimated by means of two methods, i.e., equilibrium dialysis method and ultrafiltration method. The results are summarized in Table II. From these observations, there was no statistical difference between ovalbumin-treated rats and saline-treated ones on the binding of salicylic acid with intraluminal macromolecular substances. Similar results were also obtained in the case of sulfadimethoxine which was also sensitive to systemic anaphylaxis in our previous report. ${ }^{4}$ The mean value of the binding of these drugs was less than $5 \%$ of control in all cases.

The intraluminal mucus release was also measured during systemic anaphylaxis. Results of these experiments are summarized in Table III. There was a significant increase in mucus release in the similar manner as the protein. The mean value of the mucus in the perfusate after the intravenous challenge with $0.5 \mathrm{mg}$ of ovalbumin was $30.3 \pm 10.7 \mu \mathrm{g} / \mathrm{ml}$, which was statistically significant $(p<0.02)$ from the control value $(17.6 \pm 2.8 \mu \mathrm{g} / \mathrm{ml})$. However, the enhancement in mucus release was not found in nonimmunized rats challenged with $0.5 \mathrm{mg}$ of ovalbumin intravenously.

Fig. 4 shows the relationship between the intraluminal mucus release and the absorption of salicylic acid in the same animals. The decreased absorption of salicylic acid did not correlate with the increased amount of the intraluminal mucus in the same animals and the coefficient of the correlation was -0.32 .

To determine the mucosal permeability of salicylic acid under these abnormal conditions, absorption studies were carried out using in vitro uptake method by intestinal everted sac, and the results were expressed in Fig. 5. There was no effect of the intravenous challenge with ovalbumin on the mucosal uptake of salicylic acid. Similar results were also obtained in rats immunized with bovine $\gamma$-globulin during systemic anaphylaxis. 


\section{DISCUSSION}

In the previous communications, ${ }^{3,4)}$ it was demonstrated that intestinal absorption of salicylic acid was significantly decreased during systemic anaphylaxis. However, no study was carried out to examine the duration of anaphylactic action on the drug absorption. The present study showed that the anaphylactic action lasts for at least $1 \mathrm{~h}$, and disappeared within 3-4 h (Fig. 2). From these findings, it was suggested that this anaphylactic action may be completely reversible.

In addition, attempts were made to clarify the mechanism by which systemic anaphylaxis interferes with salicylic acid absorption. It was considered that various alteration might take place in the intraluminal or membrane factors controlling the permeability of this drug. Moreover, the circulatory changes might also contri- bute to the decreased absorption of salicylic acid. ${ }^{12)}$ Among various mechanisms, the present studies were concentrated to the intraluminal interactions and the mucosal permeability as the first and second steps on the gastrointestinal absorption of salicylic acid.

The absorption of salicylic acid, which is one of the most commonly used acidic drugs, occurs by passive diffusion primarily of the nondissociated lipid-soluble molecules across gastrointestinal membranes and hence is influenced by intraluminal $\mathrm{pH}{ }^{13,14)}$ According to the $\mathrm{pH}$ partition theory, ${ }^{15)}$ if the $\mathrm{pH}$ is increased, salicylic acid is more ionized and this tends to decrease the rate of absorption. However, our results indicates that the changes in $\mathrm{pH}$ value was not observed by the antigen challenge. From these observations, the decreased absorption of salicylic acid is not due to the changes in $\mathrm{pH}$ value.

TABLE II. Binding of Salicylic Acid with Macromolecular Substances in the Perfusate Obtained from Rats with Systemic Anaphylaxis

\begin{tabular}{|c|c|c|c|c|}
\hline \multirow{2}{*}{ Drugs } & \multirow{2}{*}{ Immunization } & \multirow{2}{*}{ Challenge } & \multicolumn{2}{|c|}{ Protein binding (\%) } \\
\hline & & & Ultrafiltration & Equilibrium dialysis \\
\hline \multirow{4}{*}{$\begin{array}{l}\text { Salicylic } \\
\text { acid }\end{array}$} & $\mathrm{OA}(\mathrm{X} 1)$ & Saline & $0.9 \pm 0.3(6)$ & - \\
\hline & $\mathrm{OA}(\mathrm{X} 1)$ & OA $0.5 \mathrm{mg}$ & $0.7 \pm 0.6(5)^{a)}$ & - \\
\hline & $\mathrm{OA}(\mathrm{X} 2)$ & Saline & $1.1 \pm 0.8(4)$ & $0.4 \pm 0.5(4)$ \\
\hline & $\mathrm{OA}(\mathrm{X} 2)$ & OA $0.5 \mathrm{mg}$ & $0.7 \pm 0.5(4)^{a)}$ & $1.5 \pm 0.7(4)^{a)}$ \\
\hline \multirow{2}{*}{$\begin{array}{l}\text { Sulfadi- } \\
\text { methoxine }\end{array}$} & $\mathrm{OA}(\mathrm{X} 2)$ & Saline & $4.2 \pm 2.4(4)$ & $1.0 \pm 0.5(4)$ \\
\hline & $\mathrm{OA}(\mathrm{X} 2)$ & OA $0.5 \mathrm{mg}$ & $3.8 \pm 1.8(4)^{a)}$ & $1.4 \pm 1.1(4)^{a)}$ \\
\hline
\end{tabular}

Binding experiments were carried out in rats immunized once (X1) or twice (X2) with ovalbumin. Results are expressed as the mean $\pm S$. D. with the number of experiments in parentheses. a) not significantly different, compared to each control. $O A=$ ovalbumin.

TABLE III. Intraluminal Mucus Release during Systemic Anaphylaxis

\begin{tabular}{ccc}
\hline \hline Immunization & Challenge & Amount of mucus $(\mu \mathrm{g} / \mathrm{ml})$ \\
\hline OA & Saline & $17.6 \pm 2.8(7)$ \\
OA & OA $0.5 \mathrm{mg}$ & $\left.30.3 \pm 10.7(7)^{a}\right)$ \\
- & Saline & $23.1 \pm 3.8(5)$ \\
- & OA $0.5 \mathrm{mg}$ & $\left.18.6 \pm 6.3(5)^{b}\right)$ \\
\hline
\end{tabular}

Results are expressed as the mean $\pm S . D$. with the number of experiments in parentheses. a) $p<0.02, b)$ not significantly different, compared to each control. $O A=$ ovalbumin. 
Although the enhanced intraluminal protein was seen by the intravenous challenge with ovalbumin, no statistical difference on the binding of the drug with intraluminal macromolecular substances in the perfusate was observed during systemic anaphylactic reactions. These studies suggest that salicylic acid did not show any marked interactions with the intraluminal macromolecular substances during systemic anaphylaxis.

Nothing definite is known about the mechanism of the increased intraluminal protein in anaphylactic reactions. Murray et al. ${ }^{16)}$ have shown that the leakage of the macromolecule (PVP) caused by the increased permeability of the bowel wall was observed in rats infected with parasites. In a later communication, Ross et al. ${ }^{17)}$ also reported that following intraperitoneal sensitization of rats with rat serum containing reaginic antibody, intravenous injection of the blue dye and intraperitioneal challenge with antigen caused a release of dye into their peritoneal fluids. More recently, the report of Bloch et al. ${ }^{18)}$ appeared that the alteration in vascular and mucosal permeability which accompanies

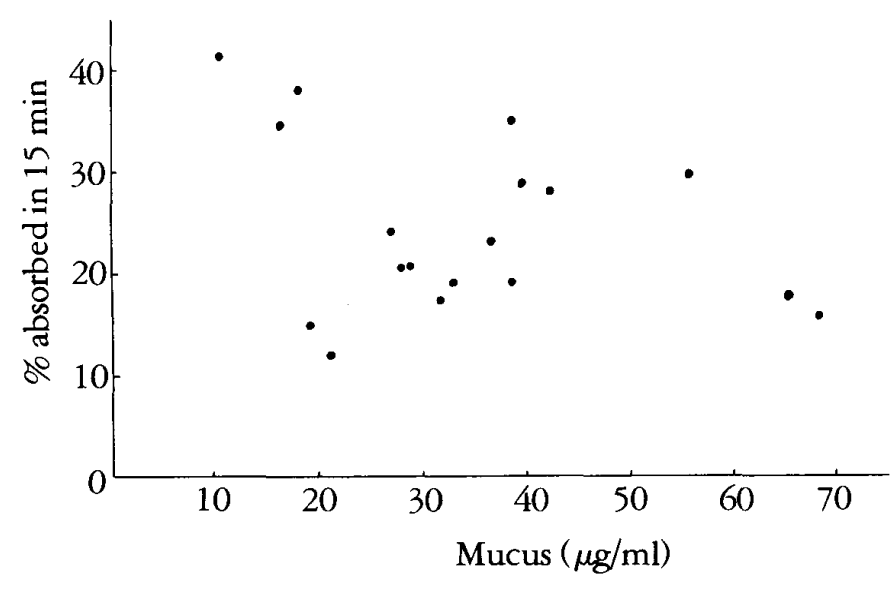

FIG. 4. Correlation between Mucus Release and the Absorption of Salicylic Acid in the Same Animals

After in situ perfusion technique, salicylic acid and mucus were determined spectrophotometrically. Numbers of plots represent the number of experiments. The coefficient of the correlation was -0.32 , which was not statistically significant. intestinal anaphylaxis was reflected by increased retention of ${ }^{125} \mathrm{I}$-labelled rat serum albumin in gut wall segments. With all these results in mind, it was suggested that the increased intraluminal protein might be caused by the leakage of plasma protein into the intestinal lumen. This suggestion was also confirmed by our studies which demonstrated the antigen-specific leakage of Evans Blue during systemic anaphylaxis. However, this does not exclude the possibility that the increased intraluminal protein might be caused by the enhanced mucus release during systemic anaphylaxis.

Moreover, under anaphylactic reactions, Lake et $a l^{19)}$ also proved the enhanced relase of goblet cell mucus. In rats actively immunized with the small doses of egg albumin and alum, and challenged with intraduodenal antigen, dosedependent and antigen-specific release of ${ }^{35} \mathrm{~S}$ -

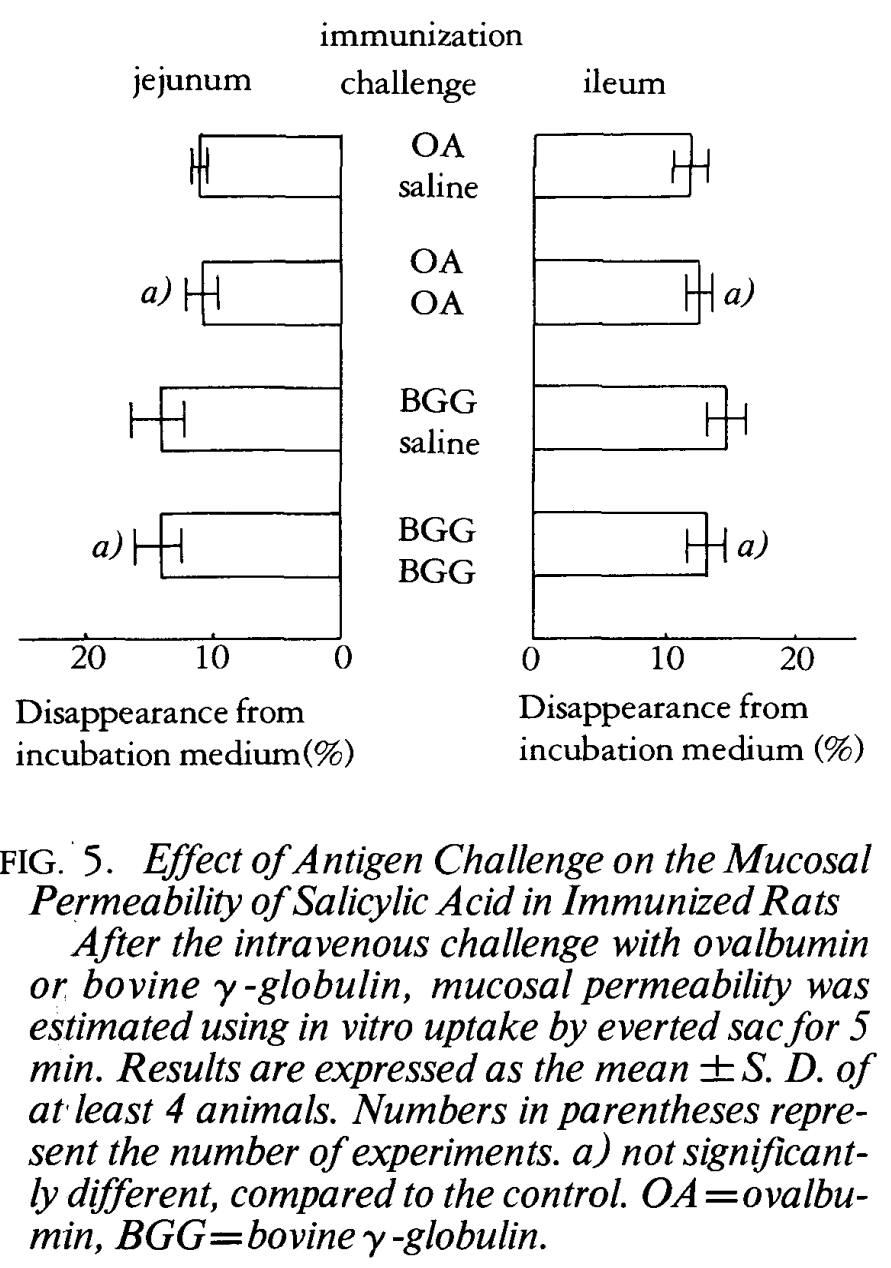


labelled high molecular weight glycoprotein presumably from goblet cells were observed. Intestinal mucus are complex glycoproteins which are secreted from goblet cells and form a gel-like covering over the mucosal surfaces. ${ }^{20)}$ They are assumed to provide lubrication and protection of underlying epithelium against potentially injurious chemicals, enzyme, bacteria and dietary constituents. Although intestinal mucus is of importance to regulate the physiological responeses in the gut, it must interfere with the secretion and absorption of many molecules through the gastrointestinal mucosa. Saggers and Lawson ${ }^{21)}$ have shown that the larger antibiotic molecules diffused more rapidly through $15 \%$ hog mucin than the smallerantibiotic molecules. Braybrooks and Burry ${ }^{22-24)}$ reported that a gastric mucin dispersion $(1 \%)$ reduced by about $50 \%$ the transmembrane movement of tetracycline as determined by in vivo rat intestinal perfusion, by in vitro everted gut method, by a diffusion cell method using cellulose acetate membrane and with a Sartorius Absorption Simulator (Sartorius-Membranefilter, GmbH, Gottingen, W. Germany). They have also demonstrated that the presence of mucin (1\%) reduced the bioavailability of phenylbutazone from the rat small intestine in vivo and in vitro. ${ }^{25)}$ Nimmerfall et al. ${ }^{26)}$ have pointed out that the absorption of compounds of different chemical structures measured in animal experiments is directly proportional to diffusion through isolated goblet cell mucin and inversely proportional to retention in the mucin. In addition, previous studies in our laboratory have shown that the mucosal surface of the small intestine, mucus layer, has an important role in the absorption process of quinine and water-soluble dyes. ${ }^{27)}$ Considering these interactions of drugs with gastrointestinal mucus, salicylic acid-mucus interactions might occur in the intraluminal fluids during systemic anaphylaxis. In an attempt to clarify these interactions, we have investigated the interaction between them but did not find any correlation (Fig. 4). This result was confirmed by our experiments which demonstrated that the binding of salicylic acid with intraluminal macromolecular substances in the perfusate was not observed (Table II). From these results, it seems likely that mucus as well as intraluminal protein might not be responsible for the decreased absorption of salicylic acid.

It is well established that anaphylaxis begins with the reaction of an antigen to a cytotropic antibody belonging to the immunoglobulin $\mathrm{E}$ class or to an immunoglobulin G subclass (cytotropic anaphylaxis) or with the formation of antigen-antibody complexes (aggregate anaphylaxis). ${ }^{28)}$ These immunological interactions trigger the release or activation of mediators such as histamine, bradykinin, serotonin, prostaglandins, rabbit aorta containing substance, slow reacting substance and anaphylatoxins. These substances are vasoactive, increase permeability, affect membrane stability and cause the release of other mediators. From the standpoint of these reports, this study was also examined to determine the mucosal permeability in anaphylactic shock. As shown in Fig. 5, no significant change was observed on salicylic acid absorption during systemic anphylaxis in comparison to controls. From these observations, it would appear that circulatory changes may play an important role in the decreased absorption of salicylic acid during systemic anaphylaxis. The next report will concern the changes in the vascular system.

\section{REFERENCES}

1) W. A. Walker: Immunology of the gastrointestinal tract: Part I, J. Pediatr., 83, 517-530 (1973).

2) W. A. Walker: Immunology of the gastrointestinal tract: Part II, J. Pediatr., 83, 711-720 (1973).

3) J. Nakamura, A. Yamamoto, S. Takada, T. Kimura, and H. Sezaki: Antigen-induced decrease of salicylic acid absorption from the small intestine in actively immunized rats, J. Pharm. Dyn., 5, 278-284 (1982).

4) A. Yamamoto, J. Nakamura, S. Takada, T. Kimura, and H. Sezaki: Effect of systemic anaphylaxis on the absorption of salicylic acid from the rat small intestine, $J$. Pharm. Sci., 73, 48-52 (1984).

5) J. Nakamura, Y. Yoshizaki, M. Yasuhara, T. Kimura, S. Muranishi, and H. Sezaki: Mechanism of the absorption of water-soluble dyes from the rat small intestine, Chem. Pharm. Bull., 24,683-690 (1976). 
6) K. Kakemi, H. Sezaki, R. Konishi, T. Kimura, and A. Okita: Effect of bile salts on the gastrointestinal absorption of drugs. II. Mechanism of the enhancement of the intestinal absorption of sulfaguanidine by bile salts, Chem. Pharm. Bull., 18, 1034-1039 (1970).

7) Y. Tokunaga, S. Muranishi, and H. Sezaki: Enhanced intestinal permeability to macromolecules. I. Effect of monoolein-bile salts mixed micelles on the small intestinal absorption of heparin, J. Pharm. Dyn., 1, 28-38 (1978).

8) M. Yasuhara, T. Yoshino, T. Kimura, S. Muranishi, and H. Sezaki: Effect of surfactants on the absorption of $p$-aminobenzoic acid from the rat small intestine, $J$. Pharm. Dyn., 2, 251 - 256 (1979).

9) N. Muranushi, M. Kinugawa, Y. Nakajima, S. Muranishi, and H. Sezaki: Mechanism for the inducement of the intestinal absorption of poorly absorbed drugs by mixed micelles. I. Effect of various lipid-bile salt mixed micelles on the intestinal absorption of streptomycin in rat, Int. J. Pharmaceut., 4, 271-279 (1980).

10) O. H. Lowry, N. J. Rosebrough, A. L. Farr, and R. J. Randall: Protein measurement with folin phenol reagent, J. Biol. Chem., 193,265-275 (1955).

11) J. H. Roe: The determination of sugar in blood and spinal fluid, J. Biol. Chem., 212, $335-343$ (1955).

12) E. Beubler and F. Lemberk: Methylxanthines and intestinal drug absorption, Naunyn-Schmiedeberg's Arch. Pharmacol., 292, $73-77$ (1976).

13) J. T. Doluisio, N. F. Billups, L. W. Dittert, E. T. Sugita, and J. V. Swintosky: Drug absorption I: An in situ rat gut technique yielding realistic absorption rates, $J$. Pharm. Sci., 58, 1196-1200 (1969).

14) H. Nogami and T. Matsuzawa: Studies on absorption and excretion of drugs. I. Kinetics of penetration of acidic drug, salicylic acid, through the intestinal barrier in vitro, Chem. Pharm. Bull., 9, 532-540 (1961).

15) P. A. Shore, B. B. Brodie, and C. A. M. Hogben: The gastric secretion of drugs: A pH partition hypothesis, $J$. Pharm. Exp. Ther., 119,361-369 (1957).

16) M. Murray, W. F. H. Jarrett, and F. W. Jennings: Mast cells and macromolecular leak in intestinal immunological reactions, Immunology, 21, 17-30 (1971).
17) J. W. Ross, H. Smith, and B. A. Spicer: Increased vascular permeability during passive peritoneal anaphylaxis in the rat, Int. Arch. Allergy Appl. Immunol., 51, 226-237 (1976).

18) K.J. Bloch and W. A. Walker: Effect of locally induced intestinal anaphylaxis on the uptake of a bystander antigen, J. Allergy Clin. Immunol., 67, 312-316 (1981).

19) A. M. Lake, K. J. Bloch, K. J. Sinclair, and W. A. Walker: Anaphylactic release of intestinal goblet cell mucus, Immunology, 39, 173-178 (1980).

20) J. F. Forstner: Intestinal mucus in health and disease, Digestion, 17, 234-263 (1978).

21) B. A. Saggers and D. Lawson: Some factors on the penetration of antibiotics through mucus in vitro, J. Clin. Pathol., 19,313-317 (1966).

22) B. W. Barry and M. P. Braybrooks: Effect of mucin on the bioavailability of tetracycline from the gastrointestinal tract: in vivo, in vitro correlations, J. Pharm. Pharmacol., 26,64P (1974).

23) M. P. Braybrooks. B. W. Barry, and E. T. Abbs: The effect of mucin on the bioavailability of tetracycline from the gastrointestinal tract: in vivo, in vitro correlations, J. Pharm. Pharmacol., 27, 508-515 (1975).

24) I. W. Kellaway and C. Marriot: The influence of mucin on the bioavailability of tetracycline, J. Pharm. Pharmacol., 27, 281-283 (1975).

25) B. W. Barry and M. P. Braybrooks: Influence of a mucin model system upon the bioavailability of phenylbutazone and warfarin sodium from the small intestine, J. Pharm. Pharmacol., 27, 74P (1975).

26) F. Nimmerfall and J. Rosenthaler: Significance of the goblet cell mucin layer, the outermost luminal barrier to passage through the gut wall, Biochem. Biophys. Res. Commun., 94,960-966 (1980).

27) J. Nakamura, K. Shima, T. Kimura, S. Muranishi, and H. Sezaki: Role of intestinal mucus in the absorption of quinine and water-soluble dyes from the rat small intestine, Chem. Pharm. Bull., 26,857-863 (1978).

28) K. Pavek: Anaphylactic shock in the monkey: its hemodynamics and mediators, Acta Anaesthesiol. Scand., 21, 293-307 (1977). 